\title{
Influence of Chemical Structure on the Mesomorphic Behaviour of 3,5-Disubstituted 1,2,4-Oxadiazoles
}

\author{
S. Torgova ${ }^{1,3}$, L. Karamysheva ${ }^{1,3}$, and A. Strigazzi ${ }^{2,3}$ \\ ${ }^{1}$ FSUE"SRC"NIOPIK" (Organic Intermediates \& Dyes Institute), \\ B. Sadovaya1/4, Moscow 103787, Russia \\ ${ }^{2}$ Dipartimento di Fisica, and Istituto Nazionale di Fisica della Materia (INFM), \\ Politecnico di Torino, C. Duca degli Abruzzi 24, I-10129 Torino, Italy \\ 3 Joint Laboratory of Orientationally Ordered Media (OOM-Lab), \\ C. Duca degli Abruzzi 24, I-10129 Torino, Italy
}

Received on 15 January, 2002

\begin{abstract}
The correlation between chemical structure and mesomorphic properties is one of the most important problems in liquid crystals science. 3,5-Disubstituted 1,2,4-oxadiazoles are very convenient model-compounds for studying the dependence of the LC properties on the molecular design. The transition temperatures and dielectric properties of 1,2,4-oxadiazoles depend significantly both on the position of the substituents with respect to the heterocycle and on their donor or acceptor features.
\end{abstract}

\section{Introduction}

The correlation between chemical structure and mesomorphic properties is one of the most important problems in liquid crystals (LC) science. Knowledge about the influence of different structural elements of the molecules on the physico-chemical characteristics of mesomorphic organic compounds allows chemists to synthesize LC with the required properties. The idea to use nonsymmetrical heterocycles as model compounds for the investigation of chemical structure influence on the mesomorphic behaviour came to us many years ago. The first heterocyclic compounds were derivatives of imidazo[2,1-b]-1,3,4-thiadiazoles [1]. These practically planar and rigid heteroaromatic systems with two condensed heterocycles, which have different $\pi$ conjugations, have never been used before as a fragment of LC molecules. The most interesting result was, that the mesomorphic properties of new mesogens were strictly dependent not only on the nature of the substituents, but also on their position in the thiadiazolic or imidazolic part of the molecule. 3,5-Disubstituted 1,2,4-oxadiazoles appeared to be even more convenient model-compounds for studying the dependence of LC properties on the molecular design.

\section{Experimental}

The synthesis of imidazo[2,1-b]-1,3,4-thiadiazoles has been described in the paper [1]. The synthesis of 1,2,4oxadiazole derivatives was carried out according to a previously reported method [2].

Transition temperatures were determined using a Mettler FP-51 thermocontroller and Leitz polarizing microscope connected to a Grundig/Polaroid recording system. The differential scanning calorimetry (DSC) data were collected by means of Perkin-Elmer apparatus.

NMR spectra were recorded on a Bruker WM-250 spectrometer, by using $\mathrm{CDCl}_{3}$ as a solvent. Satisfactory elemental analyses were obtained for all new compounds.

\section{Results and discussion}

We have synthesized and investigated a lot of imidazothiadiazolic derivatives. In Table 1 some examples of the compounds synthesized are given. Let us compare the transition temperatures and the phase sequence of these derivatives.

Compounds 1 and 2 have a very small difference in molecular structure, however, in the "reversed" structure of 2 a very narrow range nematic phase appears. 
Replacing the benzene ring with a cyclohexane one (compounds 1 and 3), we can observe only the nematic phase. The presence of a cyclohexane ring in the thiadiazolic part of the molecule causes the appearance of a nematic phase only, whereas the same ring in the imidazolic part of the molecule leads to both a smectic and a nematic phase. It is necessary to underline, that this behaviour is independent of the cyclohexane ring connection, whether it is directly connected to the central heterocyclic fragment (compounds 3, 5 and 4), or forms part of the phenylcyclohexyl fragment (compounds 7 and 6$)$.

Table 1. Transition temperatures of imidazo[2,1-b]-1,3,4-thiadiazoles.

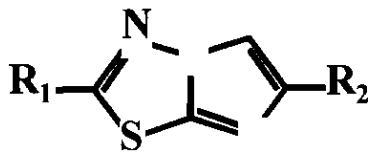

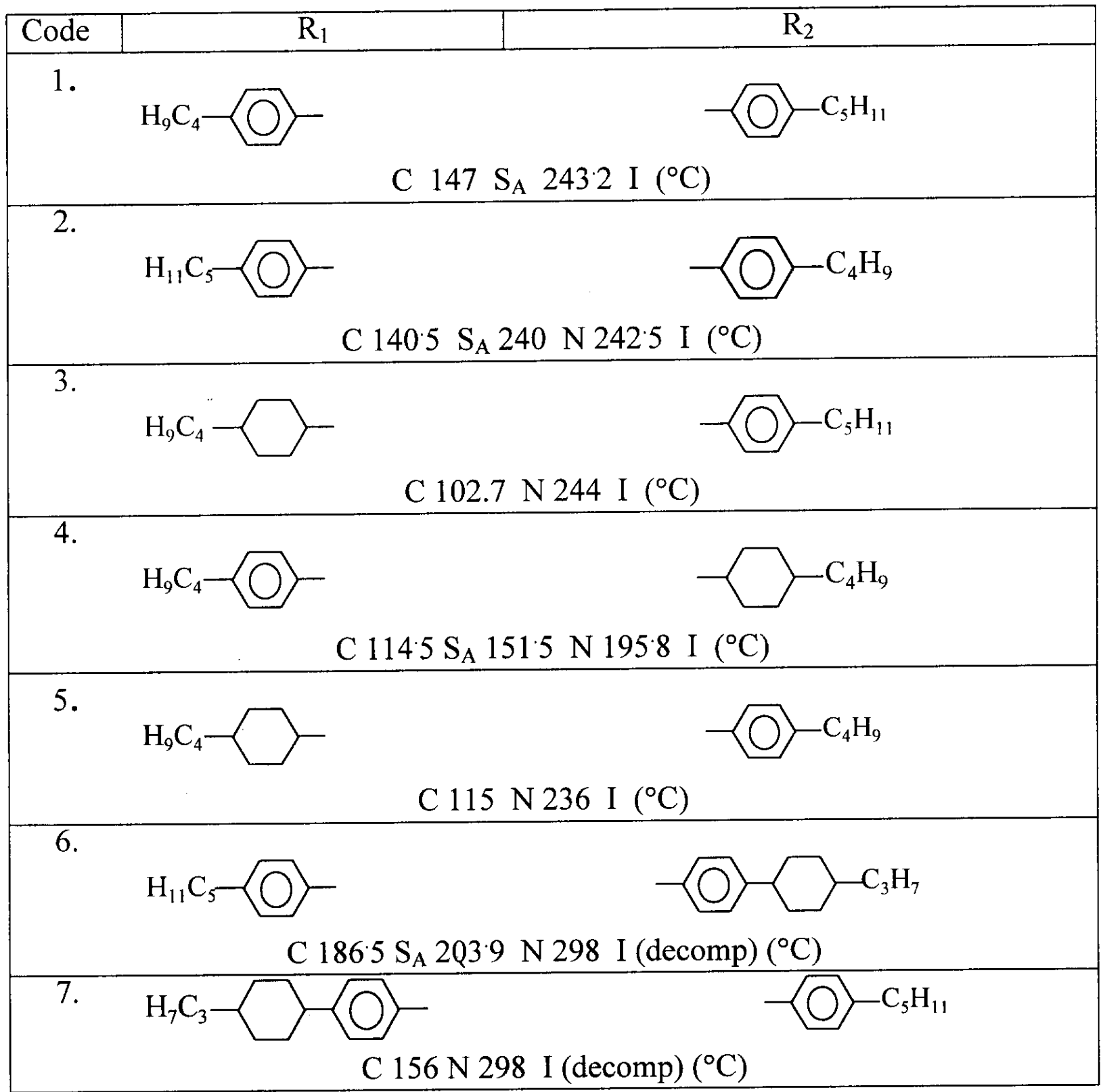


Table 2. Dependence of the 1,2,4-oxadiazoles mesomorphic properties on the position of alkyl substituents.
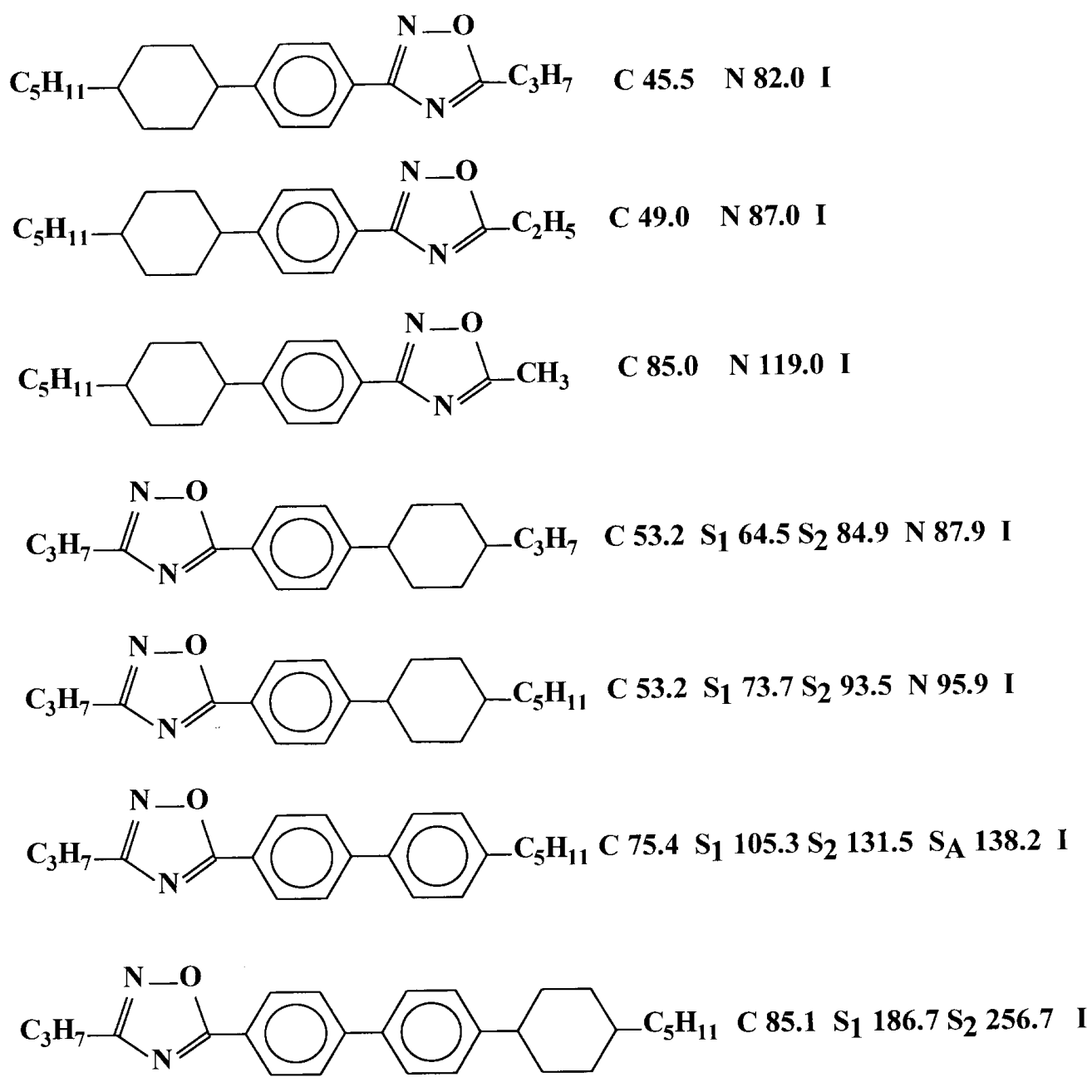

$\mathrm{C}_{3} \mathrm{H}_{7}-\mathrm{R}_{\mathrm{N}}^{\mathrm{N}-\mathrm{O}} \bigcirc \bigcirc-\mathrm{OCH}_{3} \mathrm{C} 102.0 \mathrm{~s}_{1} 114.0 \mathrm{~S}_{2} 126.0 \mathrm{~N} 133.5 \mathrm{I}$<smiles>CCOc1ccc(-c2nc(-c3ccccc3)no2)cc1</smiles>

$\mathrm{C}_{9} \mathrm{H}_{19}-\stackrel{\mathrm{N}-\mathrm{O}}{\mathrm{N}} \bigcirc-\mathrm{C}_{3} \mathrm{H}_{7} \mathrm{C} 51 \mathrm{~s}_{1} 71.7 \mathrm{~S}_{2} 88.4 \mathrm{~S}_{3} 92.2 \mathrm{~S}_{\mathrm{A}} 93.1 \mathrm{I}$

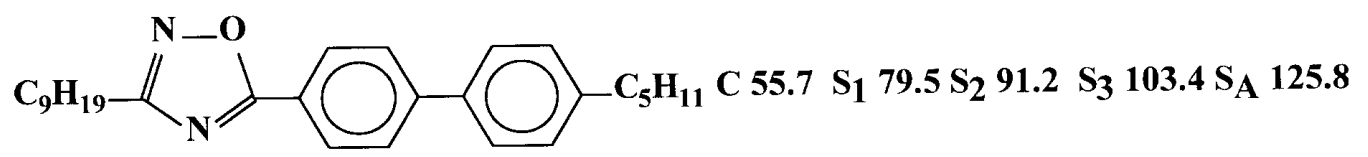


Table 3. Increasing of the molecular polarization by introduction of the polar groups in position 3 and 5 of oxadiazole increases the melting points of LC.

Weak acceptor substituent in position 3

1.<smiles>CCCCC1CCC(c2ccc(-c3nc(-c4ccccc4Cl)no3)cc2)CC1</smiles>

C $90 \quad N \quad 100 \quad I$

2.

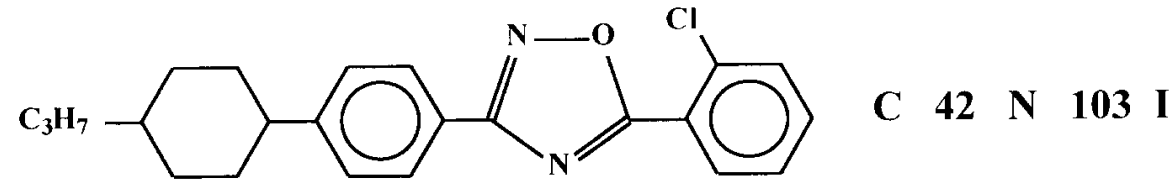

3.<smiles>CCCCCC1CCC(c2ccc(-c3nc(-c4ccccc4Cl)no3)cc2)CC1</smiles>

C 71 N 97 I

4.

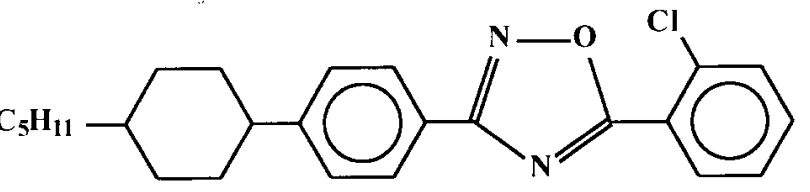

C 44 N 106 I

The strong acceptor substituent in position 5

5. $\mathrm{C}_{5} \mathrm{H}_{11}$<smiles>CCOc1ccc(-c2nc(-c3ccc(C4CCC(I)CC4)cc3)no2)cc1</smiles>

C 65 S 68 N 182 I

6.

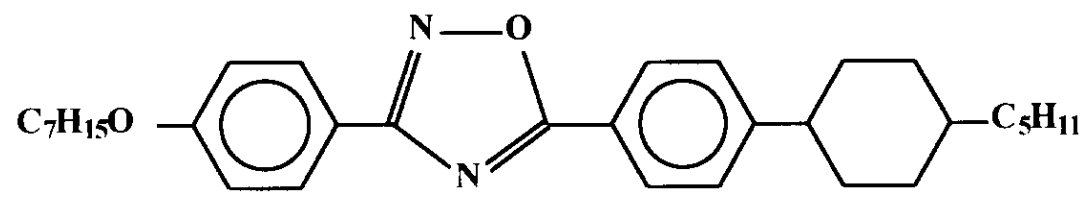

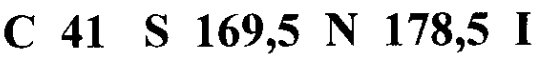

The strong acceptor substituent in position 3 leads to an increase in dielectric anisotropy (compare compounds 2 and 1 in Table 4). 
Table 4. Influence of the strong acceptor and donor substituents and cycloxexane fragment.

Strong acceptor substituent

1.

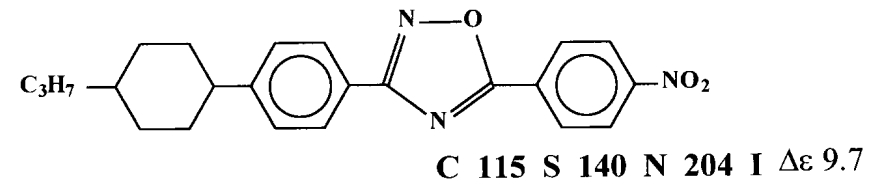

2.

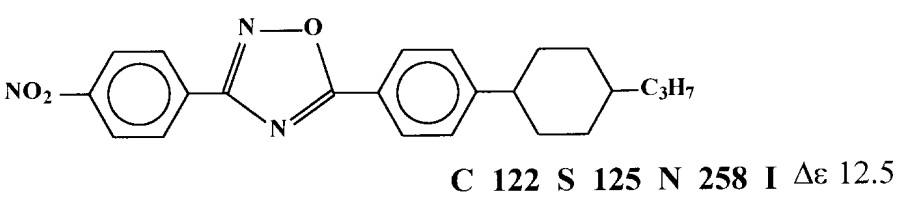

The combination of a strong donor and acceptor substituents

3.

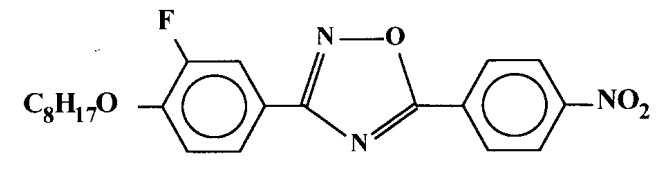

C $93 \quad \mathrm{~N} 120 \mathrm{I} \Delta \varepsilon 6.9$

4.

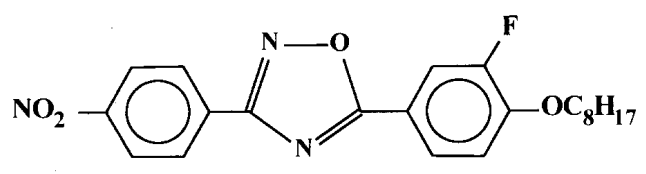

C $71 \mathrm{~S} 126$ I $\Delta \varepsilon 16.7$

The influence of trans-1,4-cyclohexane fragment on the type of the mesophase

5.

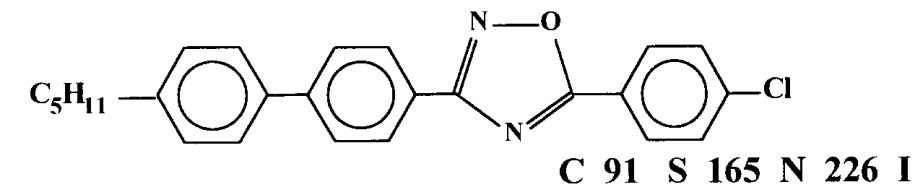

6.

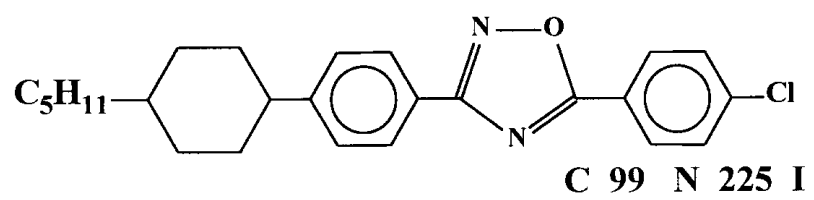

The combination of a strong donor substituent in position 3 and a strong acceptor in position 5 makes the difference in the dielectric anisotropy, compared with the "reversed" structure, more pronounced (compounds 4 and 3, Table 4). Mesogens with a trans-1,4cyclohexylene fragment have an evident nematogenic character as compared with biphenyl analogs (compounds 6 and 5, Table 4). With the help of a crosscoupling reaction, which we used for the first time for the synthesis of this class of compounds, we had the possibility to design the molecules with completely different shapes (Table 5). 
Table 5. Dependence of transition temperatures of 1,2,4-oxadiazole derivatives on the geometrical factors.

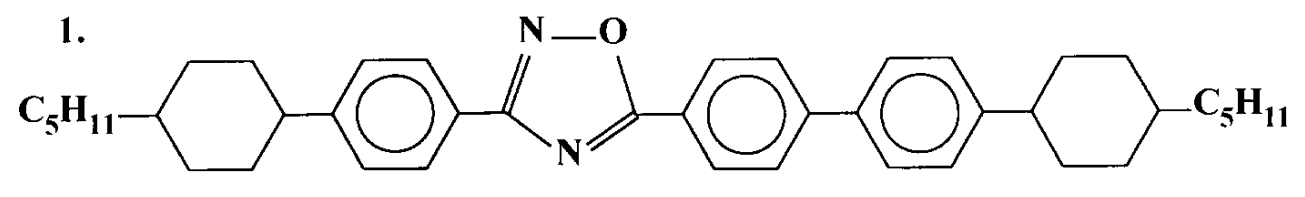

C 164 S 275 N 307 I (dec)

2.

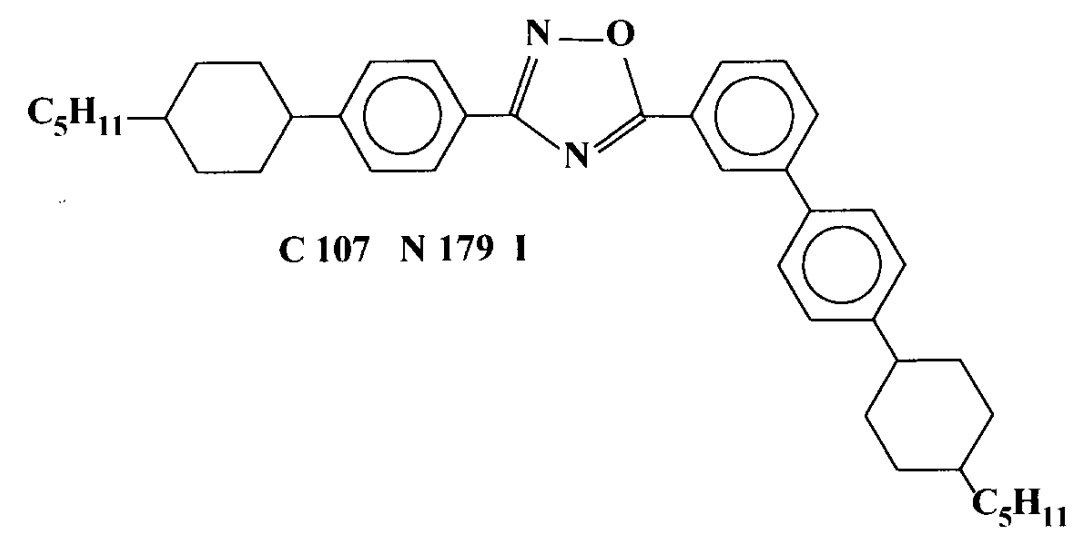

3.

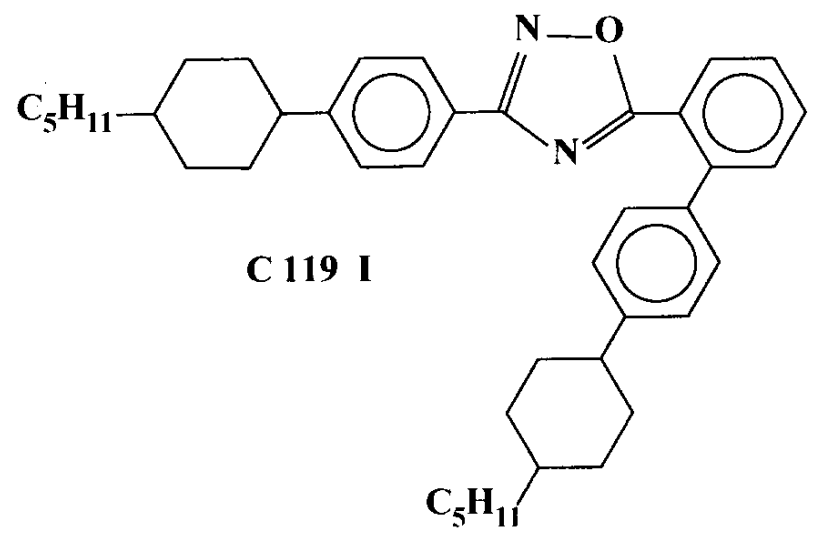

4.
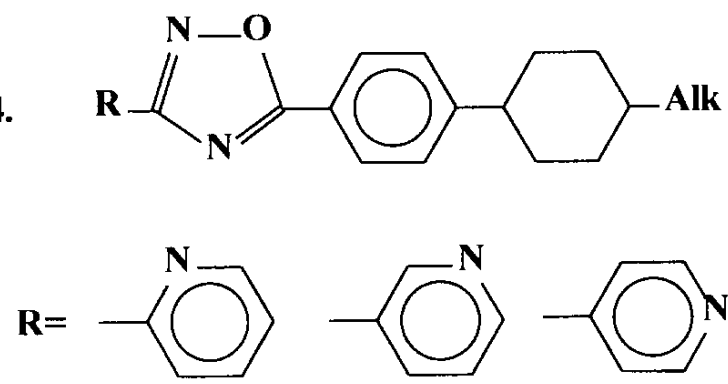<smiles>Cc1ccncc1</smiles> 
Compound 1 possesses both smectic and nematic phases. Compound 2 - has a bent molecular shape and exhibits only a nematic phase, the third compound has no mesophase at all (Table 5). The last compound was obtained in very small yield (less then 10\%). We assume that it was due to steric difficulties.

Pyridine-containing oxadiazoles were also synthesized, primarily with the purpose of checking the cor- relation between the thermal and dielectric properties of new $\mathrm{LC}$ and the position of the nitrogen atom in the pyridine ring (ortho-, meta- and para- with respect to the oxadiazolic ring, Structure 4 in Table 5).

In Table 6 the data from the thermal and dielectric measurements for the pyridine containing compounds are presented.

Table 6. Dependence of the transition temperatures of 1,2,4-oxadiazoles with pyridine substituents on the position of the nitrogen atom in the pyridine ring.

1

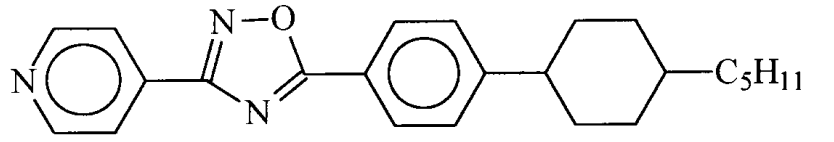

C 74.7 S 80 N $157 \mathrm{I}, \Delta \varepsilon=7.57$

2

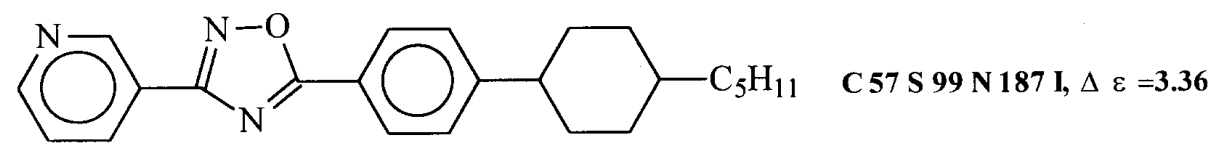

3

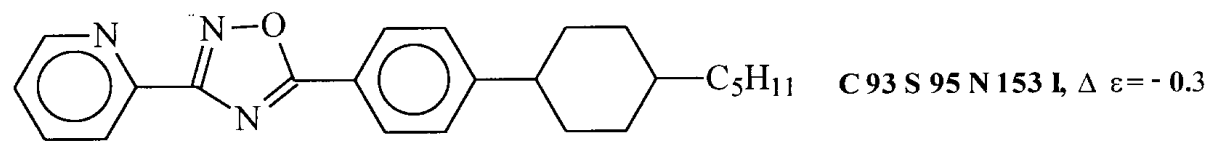

4

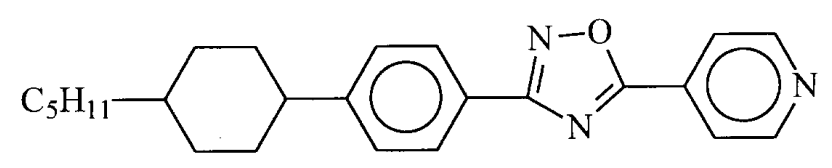

C $90 \mathrm{~N} 162.7 \mathrm{I}, \Delta \varepsilon=2.49$

Liquid crystals with meta-pyridine substituents (compound 2) have the largest mesophase interval, with para-pyridine (compound 1) they have an intermediate mesophase range, as compared with ortho-pyridine (compound 3). Moreover, oxadiazoles with parapyridine have a rather large dielectric anisotropy value (7.57), with meta-pyridine the dielectric anisotropy is around half this value (3.36), and with ortho-pyridine the value is even negative $(-0.3)$.

The influence of the position of the pyridine substituents is also evident: when it is in the diazolic part, both smectic and nematic phases are present. The introduction of a pyridine substituent in the oxazolic part of the molecule leads to the presence of the nematic phase only (compare compounds 1 and 4 ).

It is necessary to point out the peculiar behaviour of alkyl-substituted oxadiazoles. In order to decrease the melting points of oxadiazolic derivatives we have designed and synthesized a series of nonsymmetric three cycles containing molecules where one of the two substituents is an alkyl-group in the $\mathrm{C}_{3}$ or $\mathrm{C}_{5^{-}}$ positions of the 1,2,4-oxadiazole, whereas the other is a p-substituted phenyl, phenylcyclohexyl- or biphenyl fragment. An alkyl-substituent in position-3 leads to a higher melting point and a more smectogenic character, than in position-5 (Table 7).

The most interesting and unexpected results were obtained from the DSC analysis of the alkyl-substituted oxadiazoles. The phase transition enthalpies showed a peculiar behaviour. In the 3-alkyl containing series the peak of isotropic transition is much greater than those for all other transitions, including the peak of melting from crystal to mesophase. In contrast, 5-alkyl1,2,4-oxadiazoles demonstrated the traditional correlation between enthalpy peaks: the maximum energy for the crystal-smectic transition, the minimum - for the nematic-isotropic transition.

"Banana-shaped" molecules on the base of oxadiazoles were also synthesized and investigated [8]. Our aim was to synthesize "banana-shaped" esters, containing asymmetric 1,2,4-oxadiazole as a central unit (Figure 2). The direct linkage between the heterocyclic group and the phenyl rings ensures a bend of 141 in the average shape of the mesogenic core, which is 7 more than that for the 1,3,4-oxadiazolic analogues [9]. 
Table 7. Transition temperatures and phase sequence alkyl-substituted 1,2,4-oxadiazoles.

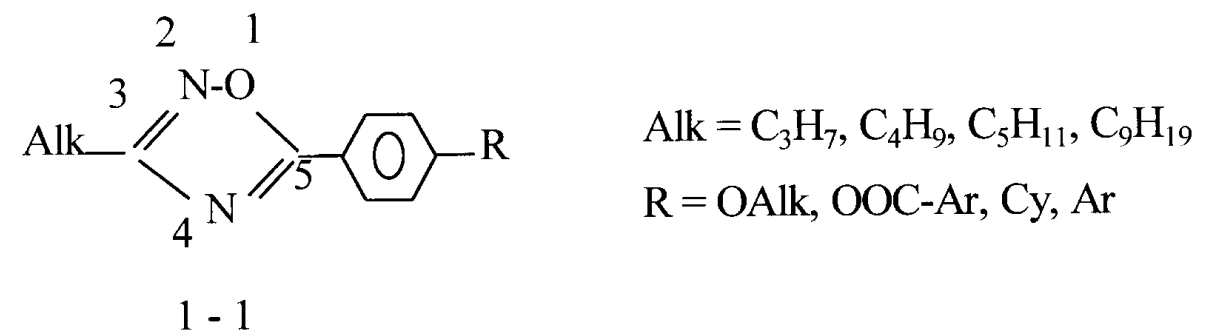<smiles>[R]c1ccc(-c2nc([AlH2])nn2C)cc1</smiles>

$13-15$

$$
\text { Alk }=\mathrm{C}_{3} \mathrm{H}_{7}, \mathrm{C}_{4} \mathrm{H}_{9}
$$$$
\mathrm{R}=\mathrm{Cy}, \mathrm{Ar}
$$

Alkyl-substituent in position-3<smiles>CCCCCc1nc(-c2ccc(-c3ccc(CCCC)cc3)cc2)no1</smiles>

Compound 10: C 79. $7 \mathrm{~S}_{1} 100.2 \mathrm{~S}_{2} 137.6 \mathrm{I}$

Alkyl-substituent in position-5

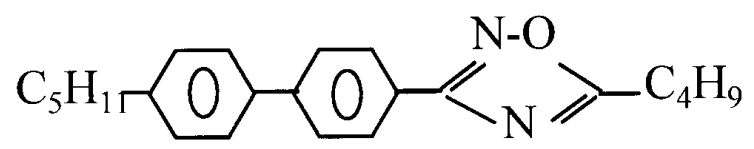

Compound 15: C $37.3 \mathrm{~S}_{1} 43.5 \mathrm{~S}_{2} 59 \mathrm{~S}_{3} 60.5 \mathrm{~N} 67 \mathrm{I}$

Compound with the lowest melting point

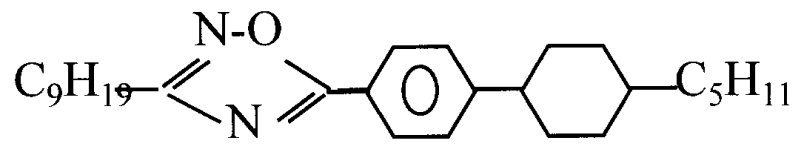

Compound 11: C 27.8 $\mathrm{S}_{\mathrm{B}} 100 \mathrm{~S}_{\mathrm{A}} 103 \mathrm{I}$ 
All new compounds synthesized exhibited a wide mesomorphic interval. The spontaneous polarization $\mathbf{P}$ in the smectic, and even in the low temperature nematic phases of this compound were measured by the method of repolarization current, by using triangle impulses. The value of $\mathbf{P}$ turned out to be of the order of $10-20 \mathrm{nC} / \mathrm{cm}^{2}$. However, at present it is impossible to unambiguously conclude, that the only contribution to $\mathbf{P}$ measured is that given by the polarization of such LC phases. This will be the subject of our further investigations.<smiles>[R]c1ccc(C(=O)Oc2ccc(-c3noc(-c4ccc(OC(=O)c5ccc([R])cc5)cc4)n3)cc2)cc1</smiles>

where $\mathrm{R}=\mathrm{C}_{7} \mathrm{H}_{15^{-}}, \mathrm{C}_{7} \mathrm{H}_{15} \mathrm{O}-, \mathrm{C}_{9} \mathrm{H}_{19} \mathrm{O}-, \mathrm{C}_{10} \mathrm{H}_{21} \mathrm{O}-$ $\mathrm{R}=\mathrm{C}_{9} \mathrm{H}_{19} \mathrm{O} \quad \mathrm{C} 70.2 \mathrm{C}_{1} 119.3 \mathrm{~S} 141.2 \mathrm{~N} 262.5 \mathrm{I}$

Figure 2. "Banana-shaped" esters, containing asymmetric 1,2,4-oxadiazole (I) as a central unit.

\section{Conclusion}

A variety of mesogenic 3,5-disubstituted 1,2,4oxadiazoles have been synthesised. The results presented here show that this new class of liquid-crystalline compounds is very useful for investigating the correlation between the chemical structure of mesogens and their mesomorphic properties.

\section{Acknowledgements}

This work was partially supported by the European Community in the frame of INCO Copernicus Concerted Action "Photocom", under Contract No. IC15CT98-0806, and in the frame of the BRITE-Euram III TN LC Photonet. Two of the authors (S.I.T. and A.S.) fully acknowledge the support of the Scientific and Organizing Committee of " 5 th Ibero-American Workshop on Complex Fluids and their Application", which enabled them to attend the Conference.

\section{References}

[1] A.V. Ivashchenko, S.I. Torgova, L.A. Karamysheva, and A.G. Abolin, Liq. Cryst. 7, 475 (1990).

[2] L.A. Karamysheva, S.I. Torgova, I.F. Agafonova, and R. Ch. Geivandov, Mol. Mater. 4, 289 (1994).

[3] L.A. Karamysheva, S.I. Torgova, I.F. Agafonova, and N.M. Shtikov, Mol. Cryst. Liq. Cryst. 160, 217 (1995).

[4] O. Francescangeli, L.A. Karamysheva, S.I. Torgova, A. Sparavigna, and A. Strigazzi, Proceedings of SPIE, 3319, 139 (1997).

[5] L.A. Karamysheva, I.F. Agafonova, and S.I. Torgova, Mol. Cryst. Liq. Cryst. 332, 407 (1999).

[6] L.A. Karamysheva, I.F. Agafonova, S.I. Torgova, B.A. Umanskii, and A. Strigazzi, Mol. Cryst. Liq. Cryst. 364, 547 (2001)

[7] Comprehensive Heterocyclic Chemistry, Eds. A.R. Katrizky and Ch.W. Rees, Pergamon Press, 6, 378 (1984).

[8] S.I. Torgova, L.A. Karamysheva, T.A. Geivandova, and A. Strigazzi, Mol. Cryst. Liq. Cryst. 365, 99 (2001).

[9] K.J.K. Semmler, T.Y. Dingemans, and E.T. Samulsky, Liq. Cryst. 24, 799 (1998). 